\title{
Professional meanings as a resource for teacher development in the space of modern innovations
}

\author{
Tatyana Shcherbakova ${ }^{1,}$, , Dinamudin Misirov $^{2}$, Sergey Semergey ${ }^{1}$ and Viktor Erovenko ${ }^{1}$ \\ ${ }^{1}$ Southern Federal University, 344006, Rostov-on-don, Russia \\ ${ }^{2}$ Don state technical University, 344010, Rostov-on-don, Russia
}

\begin{abstract}
The article describes the content of professional meanings as a resource for teacher development in the space of modern innovations. The content of the article reveals the features of the projection of professional meanings in the activity of a teacher, the influence of semantic formations on the professional development of a modern teacher. The paper describes the subjective determinants of the formation of meanings and values adequate to the teacher's mission in the context of resources and risks of the modern innovation space. The author describes the teacher as a carrier and translator of professional and personal orientations and semantic models of relationship with the world. The article describes the psychological functions of professional meanings in the activity and promotion of a teacher in the profession. Systematized criteria for the development of professional meanings of the teacher as a resource for its development in the space of modern innovations. The results of an empirical study of teachers ' ideas about the meanings of professional activity and their projections of semantic formations in real practice are presented.
\end{abstract}

\section{Introduction}

Modern educational space with a high innovation index produces special professional meanings that initiate and regulate the activity of the teacher. Components of value - semantic sphere given a vector of self-perception, esteem, and self-attitude of the individual to himself as a subject of innovative activity and creativity $[1,2]$. The contents of the system of value orientations, meanings-aspirations, subjective image of achievements form a kind of semantic evaluation matrix teacher's own resources and risks, Productivity, innovative activity and satisfaction with the outcome correlates with the degree of motivational "charge" the decision put forward new objectives. The resourcefulness of professional meanings is associated with a reflexive assessment of the personality, its behavior in the past, current or predicted situation for the teacher to model the trajectory of self-changes at various stages of professional life. One of the main functions of semantic regulation of activity in psychology is the activation of subjective resources and personal potential, optimization of the relationship "I-profession" in the context of the General system of personal relations. Adequate professional meanings help to create favorable situations of life activity in the

\footnotetext{
*Corresponding author: tatiananik@list.ru
} 
profession, due to self-change and transformation in the conditions of modern educational and social practice [3].

The formed semantic sphere is the basis of professional adaptability and success, setting an individual project of self-development, self-regulation and self-control $[4,5]$.

Professional meanings lead to the expansion of the thesaurus of purposeful pedagogical tools, ways to translate constructive models of building relationships with The world.

The research of psychologists shows that the readiness of the semantic sphere of the subject to accept and implement an innovative format of activity is a predictor of success [6, 7].

Self-assessment of psychological resources is associated with value orientations, the allocation of clusters of qualities relevant to professional meanings, generated by the meaning-making activity of the teacher in the space of modern innovations.

Professional meanings expressed and realized by the individual set a positive emotional background at various stages of innovation development, reflect the subjective position of the teacher, and support the intensity of the desire for professional growth and success [8].

The success of pedagogical activity in the space of modern innovations is determined by the formation of subjectivity, the integration of cognitive schemes and conative algorithms with value orientations, the nature of individual semantic space and the image of the world.

Professional meanings are a significant component of motivation for continuous selfdevelopment and personal growth, participating in self-initiation, modeling and regulation of these processes. The structure of the system of this type of semantic formations includes: the image of the pedagogical profession, personal meanings, individual values, professional Selfconcept, image of achievements, acceptance of the mission and adequate semantic attitudes $[9,10]$.

The subjective source of personal and meaningful professional activity of a teacher in the space of modern innovations is sociogenic needs: the need for personalization, selfrealization and self-actualization, self-affirmation as a professional [11].

Professional meanings as a resource for continuous development and self-development of the teacher in the future determine the direction of this process and evaluation markers, set the subjective bar of achievements, the Dynamics of professional and personal value orientations of the teacher reflects the reflection of the subjective experience of pedagogical activity in the innovative educational space. In the content and structure of professionalpersonal orientation of the teacher to integrate the individual-personal semantization of modern professional space, value-semantic grid professional environment nominated from outside the targets, which becomes a resource of preadaptation personality. The content of professional meanings, in essence, determines the activity of the teacher in relation to professional development, self-improvement and self-creation. Successful professional selfdevelopment is associated with the teacher's awareness of target personal orientations; understanding of the individual format of the content and time prospects of life in the profession, reflection on the hierarchy of values and the personal meaning of pedagogical activity $[12,13]$.

In the diversity and content of the system of semantic motivational motivations, we can distinguish a constructive motivational orientation, which is based on self-projecting positive development of oneself as a professional, and a non - constructive one, which focuses on achieving a situational pragmatic result [14].

In assessing the resource value of professional meanings, such parameters as stability, awareness, and effectiveness are taken into account.

Today, there is a humanistic, positive trend in the development of the semantic sphere of the teacher, immersed in the context of innovative educational space.

Semantic motivation non-situational activity professional advancement of the teacher in the space of modern innovation reflects the social and subjective standards, the viability of 
the personal scenarios, a predictive model of the future individual, the adoption of selfdevelopment as values, positive attitudes on domestic resource mobilization [15].

An important resource value is an adequate self-assessment of oneself as a carrier of relevant professional meanings and reflection of success factors, difficulties, and psychological barriers in solving the problem of meaning [16]. The space of modern innovations produces the need to accept the idea of the expediency of continuous self-change and mobilization.

In modern science, it is shown that the level of development of the subject's semantic sphere correlates with the richness and diversity of the spheres of life in which he acts as an active figure. This contextual diversity of development conditions harmonizes and integrates the semantic sphere of the teacher's personality. In the process of professionogenesis, the conceptual model of semantic interaction with oneself, others, the subject of pedagogical activity and the World is stabilized.

The set of criteria for the development of professional meanings of a teacher as a resource for its development in the space of modern innovations can be presented as follows:

- effectiveness of value-semantic constructs in making productive and pedagogically appropriate decisions;

- completeness of projections of value-semantic trends in the system of ways to implement professional behavior;

- stability of professional meanings in an entropic environment;

- compliance of the style of functioning in a real situation and methods of managing the emotional sphere with value representations and semantic installations;

- adequacy of the measure and form of representation of personal meanings and values in interaction situations and professional success.

\section{Methods}

The respondents were teachers of the Rostov region who were undergoing professional development at the Rostov Institute for advanced training and retraining of educational workers, in the number of 250 people. To collect empirical data, we used a questionnaire, a project mini-essay, and a survey.

\section{Discussion}

In the study, more than half $(65.6 \%)$ of teachers ' respondents say that they take time for selfanalysis after each lesson, $21.3 \%$ face difficulties in this type of activity, and more than $13 \%$ resort to self-analysis only when the administration insists on it.

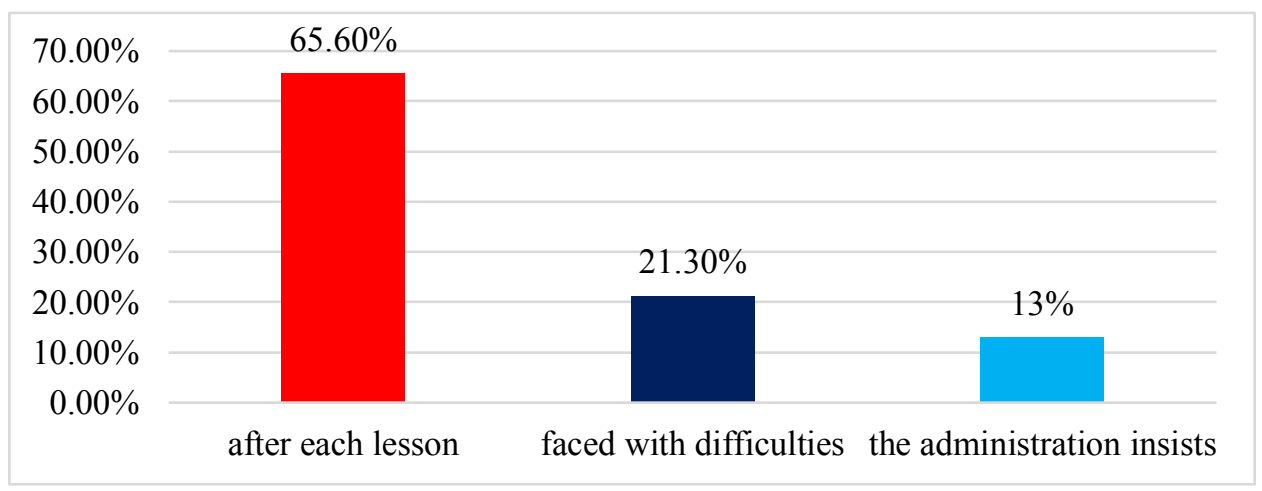

Fig. 1. Factors that trigger introspection. 
Assessing the degree of authenticity, openness in the representation of feelings, the broadcasting of attitudes and evaluation interactions with learners, colleagues and parents, teachers are the following positions: $46.3 \%$ believe that the inability to openly Express their feelings create professional complexity and lead to burnout; a $35.6 \%$ believed that this fact contributes to the development and $18.1 \%$ stress that it creates internal tension and lowers the status of professional health.

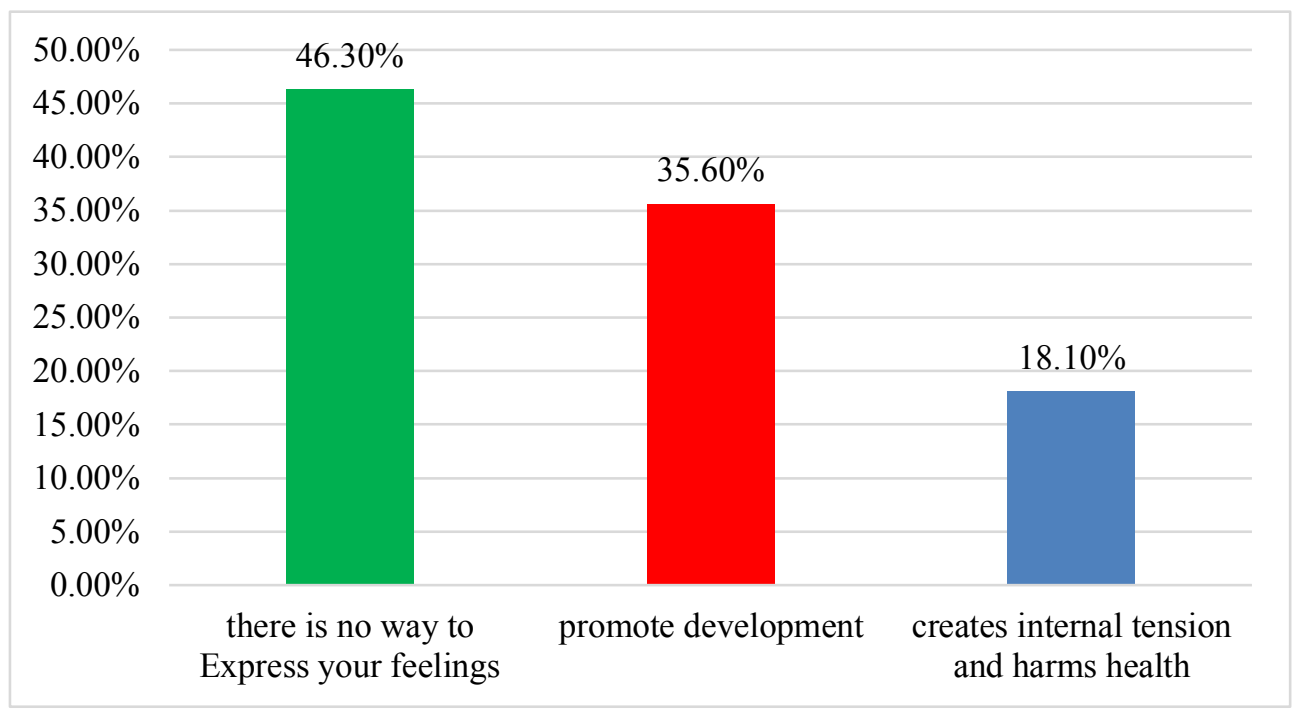

Fig. 2. The effects of barriers to authenticity.

Assessing their behavior during the lesson, more than half of teachers 55\% note that they can manage their behavior quite easily at the level of subjective control; $25.4 \%$ of respondents note difficulties in controlling behavior in the lesson, analyzing their actions and emerging effects $20.6 \%$.

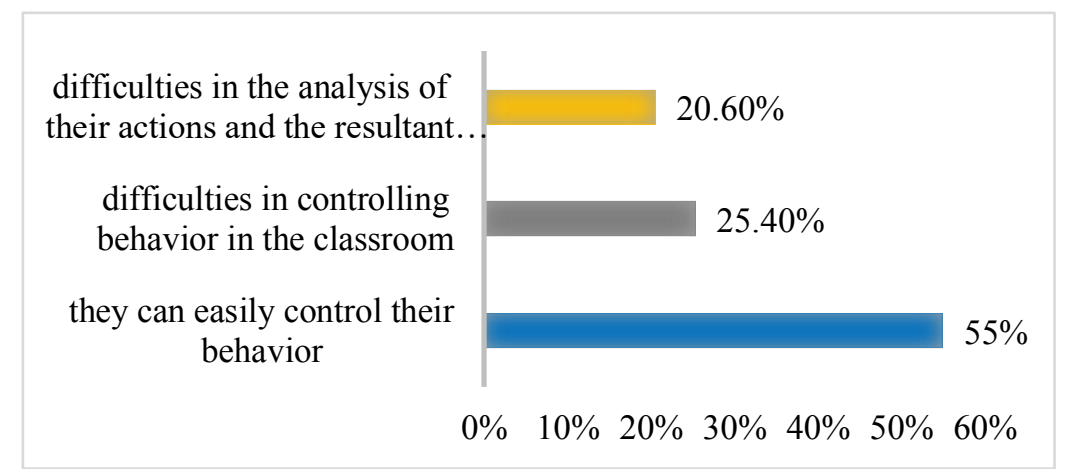

Fig. 3. Self - assessment of the ability to manage professional behavior.

Regarding opportunities for professional and personal development, $45.8 \%$ of teachers note that they regularly engage in self-development and self - improvement; $50.6 \%$ - often plans to work on themselves are not implemented due to lack of time and lack of energy. When asked about the attitude to the variety of teaching methods, programs, and concepts, most teachers note a sense of confidence in their professional capabilities, due to the availability of choice. 
At the same time, a certain number of respondents indicate that the need to constantly choose and bear responsibility for the consequences of choice causes irritation and internal tension and believe that this distracts from work.

"It seems to me that a school class filled with students before a lesson can be compared to a mountain peak" - $57.9 \%$ of teachers believe; $38.8 \%$ compare the class to "the sea, which you want to dive into and enjoy its strength and beauty", respectively, and $10.4 \%$ of respondents choose the metaphor: "a dark dense forest, which you enter with fear and do not know what awaits you".

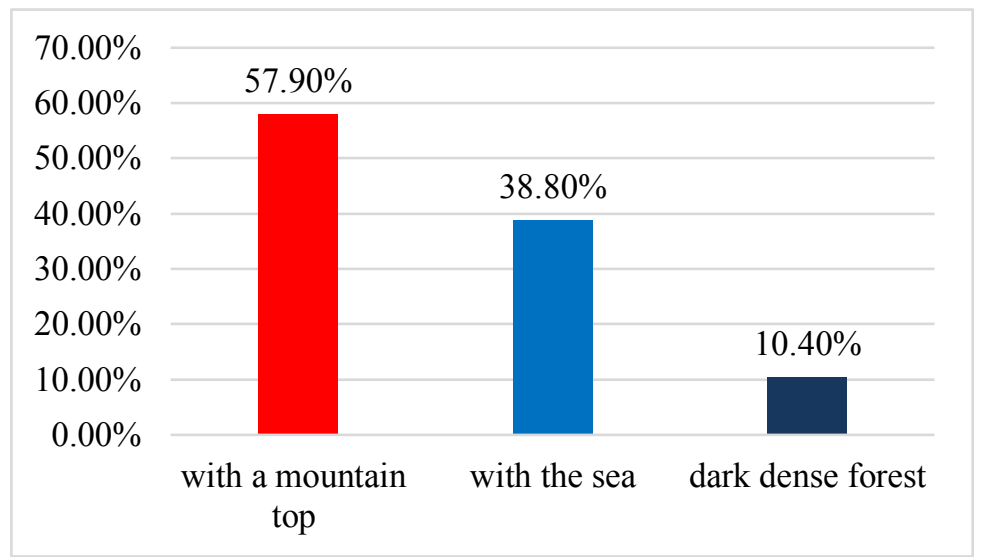

Fig. 4. Metaphorical definitions in the perception of a group of students.

If the opinions of the teacher and team members differ on a particular pedagogical situation, the overwhelming majority of respondents $(54.5 \%)$ will prefer to remain in their opinion but will act in accordance with the requirements of others. Show independence, the opinions of the teacher and team members are independent and will act as they see fit, regardless of the opinions of others, $42.1 \%$. And, a fairly small percentage of respondents are ready to change their opinion, obeying the group $-12.5 \%$

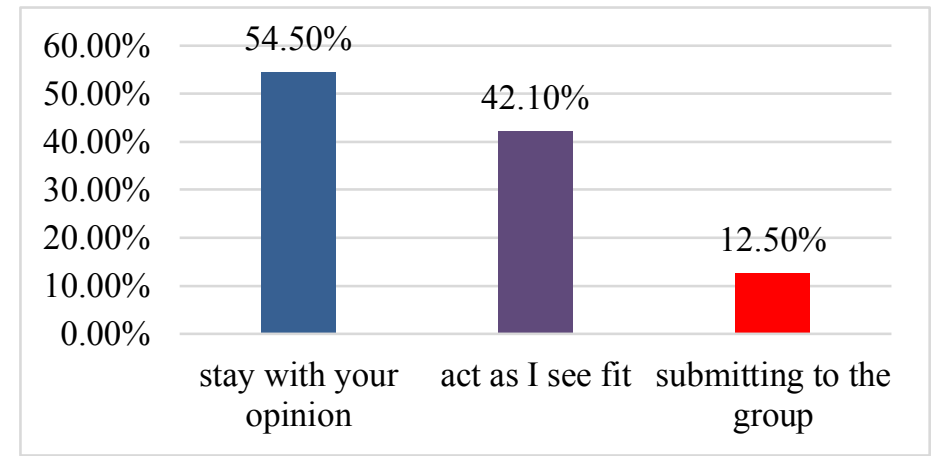

Fig. 5. Types of professional behavior in a situation of disagreement.

\section{Conclusions}

Professional meanings are a resource for the development of a teacher in the space of modern innovations, which is due to their functions: initiation and actualization, regulation and control, subjective assessment of what is happening and reflection. The resource capabilities of meanings also consist in a subjective partiality to the course and results of activity, a focus on representing oneself as a carrier of meanings and values. In the innovative educational 
space, the teacher is constantly faced with the need to solve "tasks for meaning" regarding their progress in the profession, the generation of personal meaning, meaning-making makes it possible to move to a new level of professional activity. At the same time, as the results of the study have shown, a certain part of teachers have risks related to the use of the resource of professional meanings: difficulties in understanding the significance of professional and personal growth for themselves, in assessing the prospects of promotion in the profession at the level of personal meaning, unwillingness to take responsibility for choosing a professional tool; insufficiently developed conceptual semantic subjective control. The perception of the class and the associations that arise in this regard for a small part of teachers dissonates with the meaning of pedagogical activity, which can generate an internal personal conflict.

\section{References}

1. I.V. Abakumova, T.S. Kagermazova, Semantic communications in the educational process: theory and technologies of directed translation of meanings in training (Publishing house of M. and V. Kotlyarov, Moscow-Nalchik, 2008)

2. V.S. Magun, Sociologicheskiy Zhurnal 1, 53 - 73 (2011)

3. A.G. Asmolov, Optics of enlightenment: sociocultural perspectives of subjectivity: monograph (Prosveshchenie, Moscow, 2015)

4. N.A. Astashova, O.V. Malkina, Izvestiya smolenskogo gosudarstvennogo universiteta 2(30), 315-326 (2015)

5. E.V. Jerzak, The Teacher as a subject in the professional life of subjectivity: monograph (DGTU, Rostov-on-Don, 2014)

6. N.F. Il'ina, Criteria of readiness of teachers to innovation activity in Pedagogy $7,80-$ $86(2012)$

7. I.M. Osmolovskaya, Public education 6, 182 - 188 (2010)

8. T.N. Shcherbakova, R.Kh. Malkarova, A.B. Sozaev, M.A. Anayev, R.Kh. Kulimova and S.M. Khakhetlov, Journal of Advanced Research in Dynamical and Control Systems presents peer-reviewed survey and original research articles. Coverage 2009-2015 (2017-2020) ISSN 1943023X

9. D.N. Misirov, T.N. Shcherbakova, Proceedings of the southern Federal University: Pedagogical Sciences: scientific and pedagogical journal 12, 113 - 120 (2013)

10. D.N. Misirov, T.N. Shcherbakova, Proceedings of the southern Federal University: Pedagogical Sciences: scientific and pedagogical journal 12, 042-048 (2012)

11. E.L. Umnikova, Development of professional competence of a teacher in an innovative Educational environment (Ural state pedagogical University, Yekaterinburg, 2011)

12. S.V. Vlasenko, Vector of science of Tolyatti state University. Series: Pedagogy, psychology 2, $70-73$ (2012)

13. E.P. Fedorova, Bulletin of the Moscow Institute of public administration and law 1(17), 154-157 (2017)

14. S.F. Kasatkin, People and education 2(39), 28 - 32 (2014)

15. T.N. Shcherbakova, Psychological competence of the teacher: monograph (Publishing house of GBOU DPO RO ripk and PPRO, Rostov n/D, 2010)

16. L. Darling-Hammond, Performance Evaluation of teachers: as evaluation of the effectiveness of a teacher can measure and improve teaching (Center for American progress, Washington, DC, 2010) 